Materials Sciences Division, Lawrence Berkeley National Laboratory, and

Department of Materials Science and Engineering

University of California at Berkeley

\title{
ON THE IN VITRO FRACTURE TOUGHNESS OF HUMAN DENTIN
}

\author{
V. Imbeni ${ }^{1}$, R.K. Nalla ${ }^{1}$ C. Bosi ${ }^{1}$, J.H. Kinney ${ }^{2}$, and R.O. Ritchie ${ }^{1,3}$ \\ ${ }^{1}$ Materials Sciences Division, Lawrence Berkeley National Laboratory, and \\ Department of Materials Science and Engineering, \\ University of California, Berkeley, CA 94720 \\ ${ }^{2}$ Lawrence Livermore National Laboratory, Livermore, CA 94551 \\ ${ }^{3}$ Corresponding author: Tel: (510) 486-5798; Fax: (510) 486-4881 \\ E-mail address: RORitchie@lbl.gov (R. O. Ritchie)
}

February 2002

submitted to

Journal of Biomedical Materials Research

This work was supported by the National Institutes of Health, National Institute for Dental and Craneofacial Research under Grant No. PO1DE09859. 


\title{
ON THE IN VITRO FRACTURE TOUGHNESS OF HUMAN DENTIN
}

\begin{abstract}
The in vitro fracture toughness of human dentin has been reported to be of the order of 3 $\mathrm{MPa} \sqrt{ } \mathrm{m}$. This result, however, is based on a single study for a single orientation, and furthermore involves notched, rather than fatigue precracked, test samples. The present study seeks to obtain an improved, lower-bound, value of the toughness, and to show that previously reported values may be erroneously high due to the absence of a sharp crack as the stress concentrator. Specifically, the average measured critical stress intensity, $K_{\mathrm{c}}$, for the onset of unstable fracture along an orientation perpendicular to the long axis of the tubules in dentin is found to be $1.8 \mathrm{MPa} \sqrt{\mathrm{m}}$ in simulated body fluid (Hank's Balanced Salt Solution), when tested in a three-point bending specimen containing a (nominally) atomically-sharp precrack generated during prior fatigue cycling. This is to be compared with a value of 2.7 $\mathrm{MPa} \sqrt{\mathrm{m}}$ measured under identical experimental conditions except that the bend specimen contained a sharp machined notch (of root radius 30-50 $\mu \mathrm{m}$ ). The effect of the acuity of the precrack on the fracture toughness of human dentin is discussed in the context of these data.
\end{abstract}

Keywords: Dentin, fracture toughness, fatigue, fractography, notch acuity

\section{Introduction}

Dentin is the most abundant mineralized tissue in the human tooth, physically located between the exterior enamel and the interior pulp (Fig. 1). However, there is only limited understanding of its structural performance, despite the fact that an accurate assessment of its mechanical properties is crucial for the prediction of how such factors as caries, sclerosis and aging, not to mention restorative processes, can degrade the strength of the tooth. While over five decades of research has been conducted for the purpose of evaluating these properties [e.g., 1-11], there is unfortunately little consistency in the available results.

Resistance to fracture is a critically important issue with teeth. For example, exposed root surfaces often exhibit non-carious notches in the dentin just below the enamel-cementum junction. The etiology for such lesions is believed to involve a combination of erosion, 
abrasion and abfraction [12]. While erosion is often the result of exposure to acids, abrasion is caused by the use of inappropriate dentifrice and abfraction by mechanical stresses induced by brushing and chewing. These notches serve as effective stress raisers and are often the sites of failure of the tooth due to fracture. While cusp fractures are common in posterior teeth, the anterior teeth are more susceptible to fracture in the gingiva, severing the crown of the tooth. Although such fractures have not been studied extensively, it is generally believed that they are catastrophic events induced by occlusal stresses.

In light of this, a stress-based fracture mechanics approach can provide a sound basis for the prediction of failure in human teeth. Under linear elastic conditions, an essential feature of this approach is that unstable fracture will occur when the stress intensity developed ahead of the tip of a pre-existing flaw exceeds the fracture toughness, $K_{\mathrm{c}}$, of the material, i.e.,

$$
K=Y \sigma_{\text {app }}(\pi a)^{1 / 2}=K_{\mathrm{c}}
$$

where $\sigma_{\text {app }}$ is the applied service stress, $a$ is the crack length and $Y$ is a function dependent upon the geometry and crack size and shape [13].

Despite the usefulness of this approach, however, there is little quantitative data on the toughness properties of human teeth; indeed, there appears to have only been a couple of studies to date with respect to the fracture toughness of dentin. The first of these studies, by Rasmussen et al. [10,11], uses a "work of fracture" (defined as the work per unit area to generate new crack surface) to quantify the toughness. Unfortunately, as this measurement is geometry- and sample-size dependent, their results cannot be compared quantitatively with any subsequent measurements. These authors, however, do report an influence of orientation on the toughness of dentin in that their measured work of fracture was lower for fracture perpendicular to the dentinal tubular direction compared to fracture in the plane of the tubules. However, it is difficult to find conclusive proof for such anisotropy as the scatter in their results was excessive. A subsequent study, by el Mowafy et al. [6], did utilize fracture mechanics based measurements, specifically using compact-tension specimens to measure an intrinsic fracture toughness in dentin. Using an orientation parallel to the long axis of the tubules, these authors report a $K_{\mathrm{c}}$ value of $3.08 \mathrm{MPa} \sqrt{\mathrm{m}}$ (standard deviation $0.33 \mathrm{MPa} \sqrt{\mathrm{m}}$ ) for dentin, which was found to remain constant over the temperature range $0^{\circ}$ to $60^{\circ} \mathrm{C}$. However, their experiments were carried out on notched, rather than fatigue-precracked, samples, and it 
is known from previous studies [14] on brittle bio-implant materials, specifically pyrolytic carbon for prosthetic heart valves, that the absence of a sharp precrack can severely overestimate fracture toughness values. As recent studies at Berkeley [15] have shown that fatigue cracks can be grown subcritically under cyclic loading in dentin, it is the objective of the present note to perform proper fracture toughness tests using appropriately fatigue precracked samples in order to determine an accurate measure of the fracture toughness of human dentin in vitro and to further assess the influence of notch acuity on such results. Although the anisotropy of toughness values in dentin is still somewhat unproven, measurements were made in an orientation perpendicular to the tubules in an attempt to determine a lower-bound value.

\section{Materials and Experimental Procedures}

Recently extracted human molars were used in the present study. Each tooth was sterilized using gamma radiation after extraction [16]. Sections $(\sim 1.5-2.0 \mathrm{~mm}$ thick) were prepared from the central portion of the crown and the root in the bucco-lingual direction (Fig. 1). Beams of dentin measuring approximately $0.90 \times 0.90 \times 10.0 \mathrm{~mm}$ were then obtained from these sections by wet polishing up to a 600 grit finish. These beams were then stored in Hank's Balanced Salt Solution (HBSS) at ambient temperature until testing. A micrograph of the typical structure of dentin is shown in Fig. 2; a brief description of this microstructure is given below in Section 3.1. This material has a yield strength, $\sigma_{y}$, of $\sim 75$ MPa.

Fracture toughness testing was performed in general accordance with the ASTM Standard E-399 for Plane-Strain Fracture Toughness [17], with the exception that the full thickness for a state of plane strain could not be achieved with the $0.9 \mathrm{~mm}$ thick dentin samples. According to ASTM E-399, a state of plane strain is achieved when the sample thickness is greater than $2.5\left(K_{\mathrm{c}} / \sigma_{\mathrm{y}}\right)^{2}$, i.e., significantly larger than the plastic or damage zone size of $r_{\mathrm{y}} \sim 1 / 2 \pi\left(K_{\mathrm{c}} / \sigma_{\mathrm{y}}\right)^{2}$. For dentin, this would require samples thicknesses greater than approximately $1.4 \mathrm{~mm}$ to yield a plane-strain $K_{\mathrm{c}}$ value. However, as this criterion is generally quite conservative and the damage zone was well-contained within the specimen boundaries, it is believed that the toughness values measured with the current test specimens would be very close to this lower-bound. 
Tests were conducted using the three-point bending geometry (Fig. 3) with a span between the lower two loading points equal to 5-5.5 times the width of the beam $(S=5$ $5.5 \mathrm{~W}$ ). Specimens were machined such that fracture occurred in the plane perpendicular to the long axis of the dentinal tubules. Two sets of experiments were carried out. In the first set, a sharp notch was carefully introduced into the top surface of the bend specimen using a razor blade (Figs. 3b, 3d). Typical notch depths were of the order of 50-125 $\mu \mathrm{m}$, with a root radius, $\rho$, of approximately 30-50 $\mu \mathrm{m}$. In the second set, in accordance with ASTM E-399, a precrack was grown out of the notch by cycling in fatigue (Figs. 3c, 3e); this was achieved at a load ratio (ratio of minimum to maximum loads) of $R=0.1$ and loading frequency of $2 \mathrm{~Hz}$, with a final maximum stress-intensity of $K_{\max } \sim 1 \mathrm{MPa} \vee \mathrm{m}$, i.e., well below the estimated fracture toughness of dentin. The final precrack length (notch plus precrack) was generally of the order of 100 to $200 \mu \mathrm{m}$, with a presumed atomically sharp crack tip.

In vitro fracture toughness testing of both types of specimens was conducted with an ELF $^{\circledR} 3200$ series voice-coil mechanical testing machine (EnduraTEC Inc., Minnetonka, $\mathrm{MN}$ ). Samples were loaded to failure under displacement control in HBSS at ambient temperature (to simulate physiological conditions) at a cross-head displacement rate of 0.01 $\mathrm{mm} / \mathrm{sec}$. A record of the applied loads and the corresponding displacements was simultaneously monitored during the test and analyzed for determining the fracture toughness. The displacements were obtained continuously from the stroke transducer on the testing frame. Three separate specimens were tested for each type of experiment.

Linear-elastic stress intensities, $K$, were computed from handbook solutions, specifically from the ASTM Standard E-399 for Plane-Strain Fracture Toughness [17]. For the threepoint bending specimen used:

$$
K=\left(\frac{P S}{B W^{3 / 2}}\right) f(a / W)
$$

where $P$ is the applied load, $S$ is the distance between the outer loading pins, $a$ is the crack length, $B$ and $W$ are, respectively, the specimen thickness and width, and $f(a / W)$ is dimensionless function of $a / W$ given by:

$$
f(a / W)=\frac{3(a / W)^{1 / 2}\left[1.99-(a / W)(1-(a / W))\left(2.15-3.93(a / W)+2.7(a / W)^{2}\right]\right.}{2(1+2(a / W))(1-(a / W))^{3 / 2}}
$$


Post-failure observations of the fracture surfaces were made both optically and using a scanning electron microscope.

\section{Results}

\subsection{Microstructure of dentin}

Human dentin is a hydrated composite material composed of nanocrystalline carbonated apatite mineral ( $\sim 45 \%$ by volume), type-I collagen fibrils ( $\sim 30 \%$ by volume) and fluid ( $\sim 25 \%$ by volume), with the mineral being distributed in the form of $5 \mathrm{~nm}$ thick crystallites in a scaffold created by the collagen fibrils (typically 50-100 $\mathrm{nm}$ diameter). The distinctive feature of the "microstructure" of the dentin is a distribution of 1 to $2 \mu \mathrm{m}$ diameter cylindrical tubules that run from the dentin-enamel junction to the soft, interior pulp (Figs. 12). These dentinal tubules are the paths of the odontoblast cells during tooth formation and are surrounded by a collar of highly mineralized peritubular dentin $(\sim 1 \mu \mathrm{m}$ thick $)$ and are embedded within a matrix of mineralized collagen called intertubular dentin. The mineralized collagen fibrils, which are between 50-100 $\mathrm{nm}$ in diameter, form a planar feltlike structure oriented perpendicular to the tubules [18]. The tubules can be considered to be randomly displaced about a periodic lattice [19], but with a distribution that depends on location within the tooth [e.g., 8].

\subsection{Fracture toughness evaluation}

Results of the fracture toughness testing, in the form of typical test records of the load versus displacement curves, are shown in Fig. 4 for the notched and fatigue precracked samples. Fracture toughness, $K_{\mathrm{c}}$, values were determined from the measured critical loads, $P_{\mathrm{Q}}$, for the onset of unstable fracture using Eq. (2). These calculations yielded average values of $2.72 \mathrm{MPa} \sqrt{\mathrm{m}}$ for the (apparent) fracture toughness of the notched samples and $K_{\mathrm{c}}=$ 1.79 $\mathrm{MPa} \sqrt{\mathrm{m}}$ for the (real) fracture toughness of the precracked samples of human dentin; the individual values obtained are tabulated below (Table I). Clearly, the absence of a sharp stress concentrator, specifically a fatigue precrack, acts to elevate the measured toughness of this material. Based on these results, it would appear that an appropriate value for the 
toughness of human dentin, in the orientation perpendicular to the tubules, is $K_{\mathrm{c}}=1.8$ $\mathrm{MPa} \sqrt{\mathrm{m}}$.

Table I Measured in vitro Fracture Toughness values of Human Dentin

\begin{tabular}{ccc}
\hline Precrack Type & $\begin{array}{c}\text { Root Radius, } \rho \\
(\mu \mathrm{m})\end{array}$ & $\begin{array}{c}\text { Fracture Toughness } \\
(\mathrm{MPa} \sqrt{\mathrm{m}})\end{array}$ \\
\hline Notch & 39 & 2.65 \\
Notch & 46 & 2.88 \\
Notch & 38 & 2.63 \\
Notch & 165 & 3.08 \\
Fatigue crack & $\rightarrow 0$ & 1.73 \\
Fatigue crack & $\rightarrow 0$ & 1.85 \\
Fatigue crack & $\rightarrow 0$ & 1.79 \\
\hline
\end{tabular}

* Average data after el Mowafy et al. [6].

\subsection{Fractography:}

Post-failure fractography was carried out using a scanning electron microscope for both types of test specimens. As shown in Figs. 5-7, fracture did indeed occur in the plane perpendicular to the long axis of the dentinal tubules. The distinction in the two different types of initial stress concentrators used can be clearly seen in Fig. 5, the typical fractography of a notched sample being shown in Fig. 5a and for the fatigue-cracked samples in Fig. $5 \mathrm{~b}$. These can be compared with the fracture morphology produced by cyclic fatigue in dentin in Fig. 6, and by overload failure in Fig. 7.

The path followed by the fatigue crack is relatively free of tortuosity with no evidence of any severe influence of the tubules on the crack front (generally evidenced by extensive crack front "bowing" around the tubules or by cavitation). However, there does seem to be some evidence, albeit not totally conclusive, of pullout behavior of the peritubular dentin cuff surrounding the tubules (indicated by arrows in Figs. 6-7), suggesting the possibility of some degree of extrinsic toughening. No evidence could be found for the presence of fatigue striations, however, in contrast to many metallic and polymeric materials. Furthermore, unlike such materials where there are generally significant differences between the fracture 
modes, and hence the fractography, of fatigue and overload fracture [20], there was little difference in dentin between the morphology of fracture surfaces obtained during cyclic fatigue-crack growth and final overload (fast) fracture (Figs. 6-7). This is typical of most brittle solids, e.g., ceramic materials such as silicon nitride and pyrolytic carbon [14,20], where the mechanisms of crack advance ahead of the crack tip are essentially identical under alternating and single-cycle (overload) loading. In such brittle materials, the mechanistic effect of cyclic fatigue loading is invariably seen behind the crack tip in the form of a progressive degradation in the operative crack-tip shielding (toughening) mechanisms [21]. Whether these mechanisms are relevant to the fatigue of dentin is currently under study.

In this regard, it is interesting to speculate whether the tubules in dentin serve as effective stress-raisers and hence as crack-initiation sites. Although this issue has never been addressed adequately, support for this possibility is provided by the common occurrence of microcracks in the peritubular dentin surrounding the tubules (Fig. 8) on the fracture surfaces obtained at the higher stresses associated with final overload failure.

\section{Discussion}

The present work appears to be only the second study in archival literature, after Ref. [6], to quantify the $K_{\mathrm{c}}$ fracture toughness properties of human dentin. This seems somewhat surprising in view of the significant work reported on the mechanical properties of other biological material systems, such as on the fracture toughness of bone [e.g., 22-24]. Nevertheless, the currently measured fracture toughness of $K_{\mathrm{c}}=1.79( \pm 0.06) \mathrm{MPa} \sqrt{\mathrm{m}}$ for dentin (measured in a fatigue-precracked sample with fracture occurring perpendicular to the long axis of the tubules) represents a figure that is $\sim 34 \%$ lower than the value of 2.72 $\mathrm{MPa} \vee \mathrm{m}$. obtained for dentin using a sharp notched sample. Based on our current results which clearly show that the fracture toughness in dentin can be elevated by using a less than atomically sharp stress concentrator, i.e., the apparent toughness was increased by over $50 \%$ using a sharp machined notch (with a root radius, $\rho$, of 30-50 $\mu \mathrm{m}$ ), it is our contention that a value of $1.79 \mathrm{MPa} \vee \mathrm{m}$. would be a reasonable estimate of the actual fracture toughness of dentin in this orientation. It should be noted here that the earlier work of el Mowafy et al. [6], where an average value of $3.08 \mathrm{MPa} \sqrt{\mathrm{m}}$ for an orientation parallel to the tubules was

reported, appears to represent an overestimate of the $K_{\mathrm{c}}$ toughness due to the fact that these 
authors utilized a relatively blunt rounded notch (with $\rho \sim 165 \mu \mathrm{m}$ ) instead of a sharp fatigue precrack in their fracture toughness test samples. There is a possibility that the difference in $K_{\mathrm{c}}$ values may additionally be associated with orientation, as Rasmussen et al. [10,11] have suggested that tubule orientation and distribution can affect the fracture resistance in dentin. Indeed, these authors measured a $\sim 50 \%$ lower work of fracture in the plane of the collagen fibrils (perpendicular to the tubules), compared to the orthogonal direction cutting the fibrils, suggesting that mineralized collagen fibrils and the tubules might play a role in any toughening mechanisms involved; however, as noted above, it is difficult to draw firm conclusions as their toughness measurements were highly size-dependent and subject to excessive scatter (specifically, with average measure errors of $12-15 \%$ and root mean square deviations of $33-60 \%$ ).

With respect to the critical issue of the type of stress concentrator used in measuring the toughness, similar observations have been made for pyrolytic carbon, where the early fracture toughness measurements using machined notches by More et al (2.79 \pm 0.23 $\mathrm{MPa} \sqrt{\mathrm{m}}$ ) [25] were over $50 \%$ higher than the values measured ahead of sharp fatigue precracks by Dauskardt et al. $(1.29-1.84 \mathrm{MPa} \sqrt{\mathrm{m}})$ [14]. Indeed, it is well known that the toughness of both ductile and brittle materials can vary substantially with the root radius of the notch used [e.g., 26,27]; specifically, early studies suggested that the apparent toughness should scale with the square root of the notch radius, i.e., $K_{\mathrm{c}} \propto \rho^{1 / 2}$. This is evident from the present work where the apparent toughness of dentin is plotted as a function of the square root of the notch radius (Fig. 9). The data from Ref. [6] is also included for the purpose of comparison. Clearly, the fracture toughness measured ahead of a sharp fatigue precrack not only provides a lower-bound value but also represents a more appropriate quantification of the intrinsic fracture resistance of the material.

Finally, it is of interest to note how this corrected fracture toughness value for dentin of $K_{\mathrm{c}}=1.79 \mathrm{MPa} \sqrt{\mathrm{m}}$ compares with the toughness properties of other biological and bioimplant material systems associated with dentistry. For example, a fracture toughness of 0.23-6.56 MPa $\sqrt{\mathrm{m}}$ has been reported for cortical bone [28], which is similar in composition to dentin in living tissue, whereas the toughness of human dental enamel is quoted as 0.71.27 $\mathrm{MPa} \sqrt{\mathrm{m}}$ [29], although the latter values were obtained using micro-indentation techniques which often tend to be approximate. By comparison, most dental cements have 
toughnesses in the range $0.1-0.5 \mathrm{MPa} \sqrt{\mathrm{m}}$, amalgams in the range 0.1-1.6 $\mathrm{MPa} \sqrt{\mathrm{m}}$, and dental composites in the range 0.6-2.0 MPa $\sqrt{\mathrm{m}}[30]$.

\section{Conclusions}

Based on an experimental study of the intrinsic fracture toughness of human dentin in vitro, the following conclusions can be made:

1. The fracture toughness of dentin has been accurately measured in Hank's Balanced Salt Solution to be $K_{\mathrm{c}}=1.79( \pm 0.06) \mathrm{MPa} \sqrt{\mathrm{m}}$ for fracture perpendicular to the tubule orientation.

2. This effect of notch acuity on the measured fracture toughness was demonstrated for dentin by measurements of an apparent increase fracture toughness value with increasing notch root radius. Indeed, the apparent toughness was shown to be directly proportional to the square root of the notch radius, and was increased by over $50 \%$ by using a sharp machined notch (with a 30-50 $\mu$ m root radius) rather than a fatigue precrack.

3. This value $(1.79 \mathrm{MPa} \vee \mathrm{m})$ is $\sim 42 \%$ lower than the only other fracture toughness value reported for dentin in the literature, specifically $K_{\mathrm{c}}=3.08 \mathrm{MPa} \sqrt{\mathrm{m}}$ by el Mowafy et al. [6]. The discrepancy between the current and previous $K_{\mathrm{c}}$ results is attributed to a difference in the orientation investigated and primarily to the effect of the notch acuity on the toughness value. The current study was performed using atomically sharp fatigue precracks in accordance with ASTM Standards, whereas the prior result was measured on samples containing machined notches.

4. It is concluded that for an accurate assessment of the intrinsic fracture toughness of biological materials, it is imperative that a sharp crack-like stress concentrator is used to initiate fracture. The use of even sharpened machined notches can significantly, and erroneously, elevate the measured fracture toughness value.

\section{Acknowledgments}

This work was supported in part by the National Institutes of Health, National Institute for Dental and Craneofacial Research under Grant No. PO1DE09859. The authors wish to thank Profs. G.W. Marshall and S.J. Marshall for their support, and Prof. M. Staninec and 
Ms. G. Nonomura for assistance with specimen preparation. The authors also wish to thank EnduraTEC Inc., Minnetonka, MN for the use of their ELF ${ }^{\circledR} 3200$ series testing machine.

\section{References}

1. Craig RG, Peyton FA. Elastic and mechanical properties of human dentin. J Dent Res 1958;37:710-718.

2. Lehman ML. Tensile strength of human dentin. J Dent Res 1967;46:197-201.

3. Cooper WE, Smith DC. Determination of shear strength of enamel and dentin. J Dent Res 1968;47:997p.

4. Renson CE, Boyde A, Jones SJ. Scanning electron microscopy of human dentin specimens fractured in bend and torsion tests. Arch Oral Biol 1974;19:447-457.

5. Renson CE, Braden M. Experimental determination of rigidity modulus, Poisson's ratio and elastic limit in shear of human dentin. Arch Oral Biol 1975;20:43-47.

6. el Mowafy OM, Watts DC. Fracture toughness of human dentin. J Dent Res 1986;65:677681.

7. Balooch M, Wu-Magidi IC, Balazs A, Lundkvist AS, Marshall SJ, Marshall GW, Brekhaus WJ, Kinney JH. Viscoelastic properties of dimineralized human dentin measured in water with atomic force microscope (AFM)-based indentation. J Biomed Mater Res 1998;40:539-544.

8. Povolo F, Hermida EB. Measurement of the elastic modulus of dental pieces. J. Alloys Compounds 2000;310:392-395.

9. Balooch M, Demos SG, Kinney JH, Marshall GW, Balooch G, Marshall SJ. Local mechanical and optical properties of normal and transparent root dentin. J Mater Sci: Mater Medicine 2001;12:507-514.

10. Rasmussen ST, Patchin RE, Scott DB, Heuer AH. Fracture properties of human enamel and dentin. J Dent Res 1976;55:154-164.

11. Rasmussen ST, Patchin RE. Fracture properties of human enamel and dentin in an aqueous environment. J Dent Res 1984;63:1362-1368.

12. Levitch LC, Bader JD, Shugars DA, Heymann HO. Non-carious cervical lesions. J Dent Res 1994;22:195-207.

13. Knott JF. Fundamentals of fracture mechanics. London, U.K.: Butterworth \& Co. (Publishers) Ltd; 1976. 
14. Dauskardt RH, Ritchie RO, Takemoto JK, Brendzel AM. Cyclic fatigue and fracture in pyrolytic carbon-coated graphite mechanical heart-valve prostheses: Role of small cracks in life prediction. J Biomed Mater Res 1994;28:791-804.

15. Nalla RK, Imbeni V, Kinney JH, Staninec M, Marshall SJ, Marshall GW, Ritchie RO. On the behavior of human dentin under in vitro cyclic fatigue. in preparation.

16. White JM, Goodis HE, Marshall SJ, Marshall GW. Sterilization of teeth by gamma radiation. J Dent Res 1994;73:1560-1567.

17. ASTM E 399-90 (Reapproved 1997), Annual Book of ASTM Standards, Vol. 03.01: Metals- Mechanical testing; Elevated and low-temperature tests; Metallography, West Conshohocken, PA: ASTM; 2001.

18. Jones SJ, Boyde A. Ultrastructure of dentin and dentinogenesis. In: Linde, editor. Dentin and dentinogenesis. Boca Raton, FL: CRC Press; 1984. 1(of 2):p 81-134.

19. Kinney JH, Oliveira J, Haupt DL, Marshall GW, Marshall SJ. The spatial arrangement of tubules in human dentin. J Mater Sci: Mater Medicine 2001;12:743-751.

20. Ritchie RO, Dauskardt RH, Pennisi FJ. On the fractography of overload, stress corrosion and cyclic fatigue failures in pyrolytic-carbon materials used in prosthetic heart-valve devices. J Biomed Mater Res 1992;26:69-76.

21. Ritchie RO. Mechanisms of fatigue-crack propagation in ductile and brittle solids. Int J Fract 1999;100:55-83.

22. Norman TL, Vashishth D, Burr DB. Fracture toughness of human bone under tension. J Biomech 1995;28:309-320.

23. Zioupos P. Recent developments in the study of failure of solid biomaterials and bone: 'fracture' and 'pre-fracture' toughness. Mater Sci Eng C 1998;6:33-40.

24. Lucksanasombool P, Higgs WAJ, Higgs RJED, Swain MV. Fracture toughness of bovine bone: influence of orientation and storage media. Biomaterials 2001;22:3127-3132.

25. More RB, Haubold AD, Beavan LA. Fracture toughness of pyrolite carbon. Trans Soc Biomater 1989;12:180p.

26. Ritchie RO, Francis B, Server WL. Evaluation of Toughness in AISI 4340 Alloy Steel Austenitized at Low and High Temperatures. Metall Trans A 1976;7A:831-838.

27. Ritchie RO, Horn RM. Further Considerations on the Inconsistency of Toughness Evaluation of AISI 4340 Steel Austenitized at Increasing Temperatures. Metall Trans A 1978;9A:331-341.

28. Behiri JC, Bonfield W. Fracture mechanics of bone- The effects of density, specimen thickness and crack velocity on longitudinal fracture. J Biomech 1984;17:25-34. 
29. Hassan R, Caputo AA, Bunshah RF. Fracture toughness of human enamel. J Dent Res $1981 ; 60: 820-827$.

30. Lloyd CH. Resistance to fracture in posterior composites: Measurement of their fracture toughness and a comparison with other restorative materials. British Dental Journal 1983;155:411-414 (1983). 


\section{List of Figures}

Figure 1: Schematic illustrating a typical human tooth with the section (shown by dotted lines) made for the purpose of specimen preparation. Note the tubules running from the dentin-enamel junction to the pulp of the tooth.

Figure 2: Micrograph illustrating the typical microstructure of human dentin. The most striking feature is the pseudo-periodically placed 1-2 $\mu \mathrm{m}$ diametered tubules.

Figure 3: (a) Three-point bending configuration utilized for the measurement of the fracture toughness, showing schematic illustrations of (b) the rounded-notch and (c) the sharp-crack configurations. (d) Optical micrograph of the notch-tip for a notch used for notch toughness tests. (e) Scanning electron micrograph of the tip of a typical precrack used for the cracktoughness tests.

Figure 4: Representative load/displacement curves obtained for the measurement of the fracture toughness ahead of (a) a machined notch and (b) a fatigue precrack.

Figure 5: An overview of the fracture surfaces obtained by fracture ahead of (a) a machined notch and (b) a fatigue precrack. The nominal direction of crack growth is also indicated.

Figure 6: Low- and high-magnification scanning electron micrographs of the cyclic fatigue region of the precrack used for the true $K_{\mathrm{c}}$ determination. There is some evidence of pullout of the peritubular dentin cuffs (indicated by white arrows). The nominal direction of crack growth is also indicated.

Figure 7: Low- and high-magnification scanning electron micrographs of the overload (fast) fracture region of a specimen used for true $K_{\mathrm{c}}$ determination. It is evident that although this fracture surface is slightly more "rough" at a macroscopic size-scale, it is essentially identical to that obtained by cyclic fatigue at microscopic size-scales. There is again some evidence of pullout of the peritubular dentin cuffs (indicated by white arrows). The nominal direction of crack growth is also indicated.

Figure 8: (a) A typical micrograph of the overload fracture region is shown, along with (b) a magnified image of the indicated region. The crack formation in the peritubular dentin is apparent. The nominal direction of crack growth is also indicated.

Figure 9: The apparent fracture toughness values for dentin are plotted as a function of the square root of the notch root radius. The corresponding notch radii are also shown. Results are shown for the present investigation along with the single data point of el Mowafy et al. [6] for comparison. 


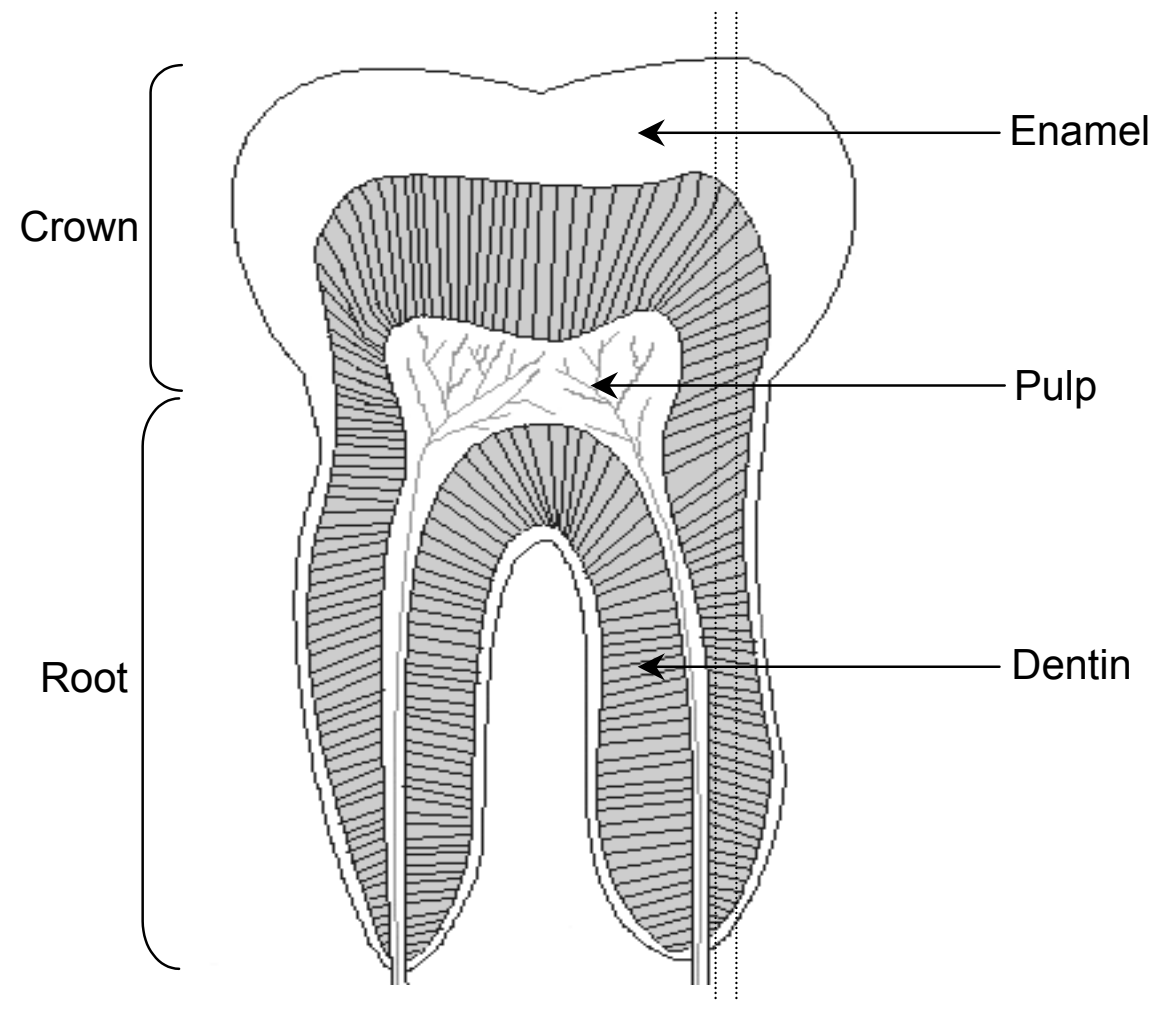

Figure 1 Schematic illustrating a typical human tooth with the section (shown by dotted lines) being made for the purpose of specimen preparation. Note the tubules running from the dentin-enamel junction to the pulp of the tooth. 


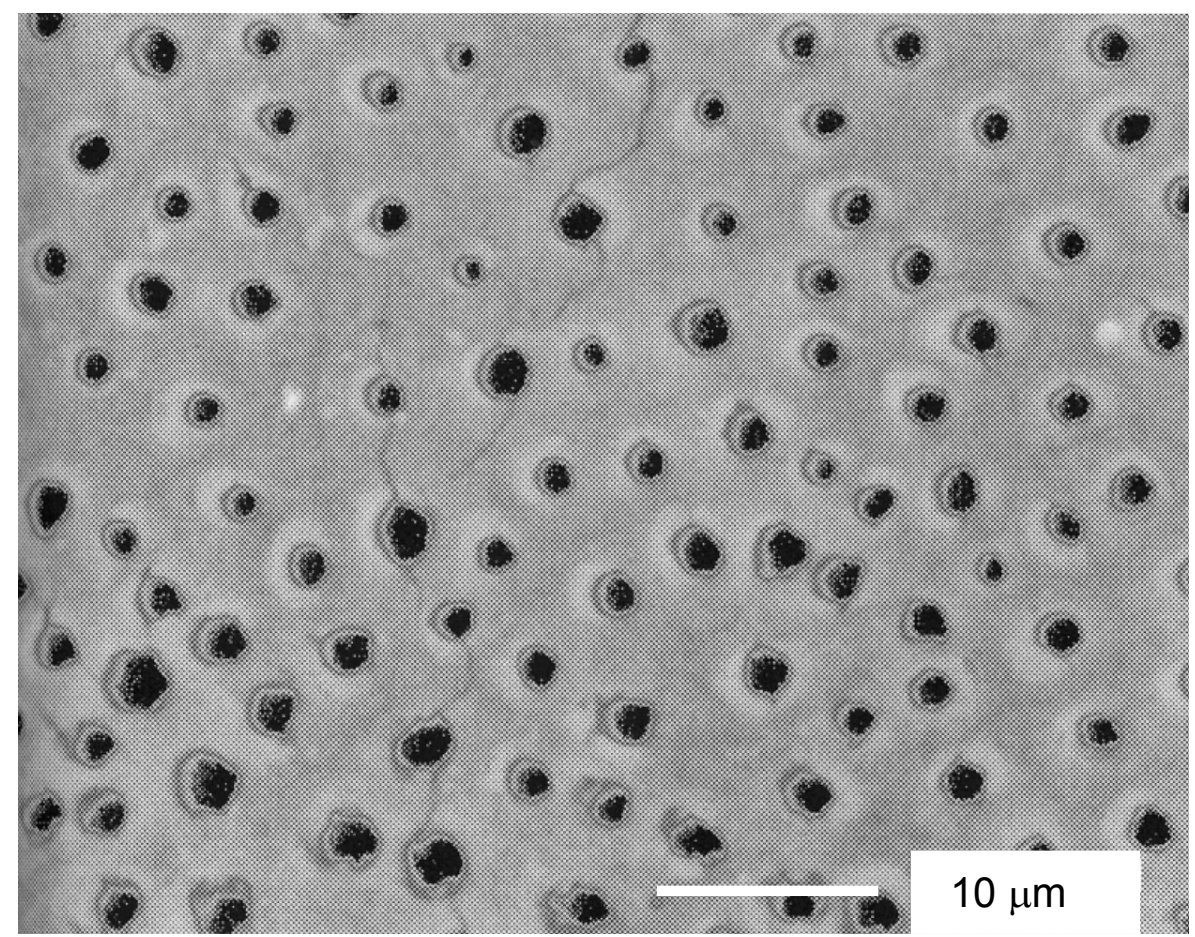

Figure 2 Micrograph illustrating the typical microstructure of human dentin. The most striking feature is the pseudo-periodically placed $1-2 \mu \mathrm{m}$ diametered tubules. 
(a)

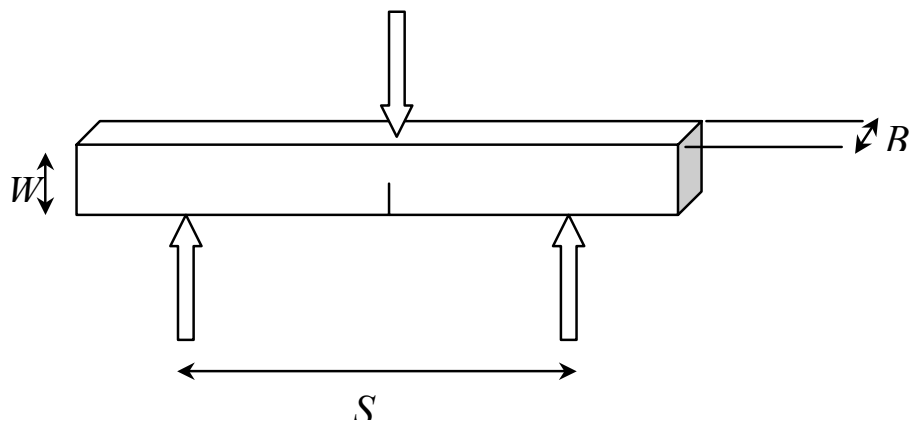

(b)
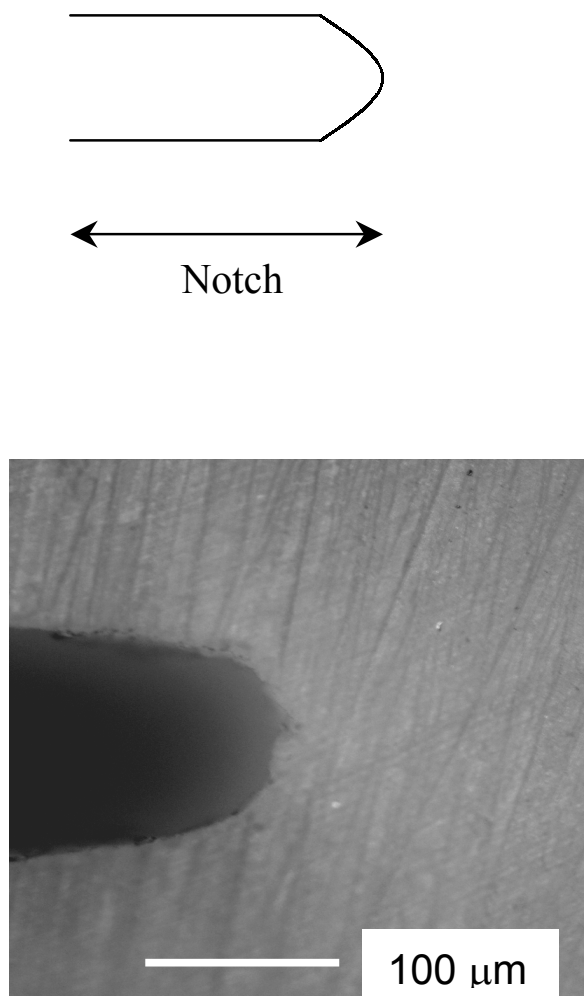

(d)

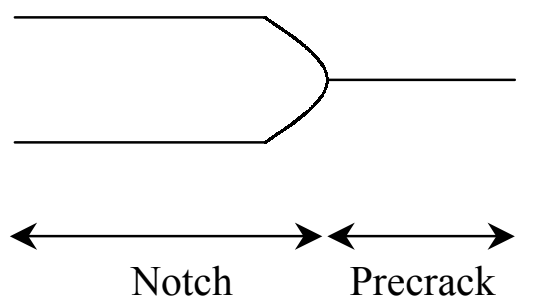

(c)

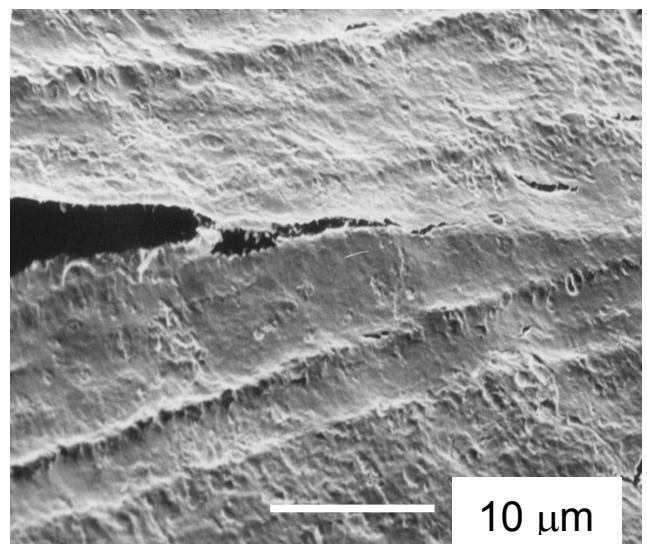

(e)

Figure 3 (a) Three-point bending configuration utilized for the measurement of the fracture toughness, showing schematic illustrations of (b) the rounded-notch and (c) the sharp-crack configurations. (d) Optical micrograph of the notch-tip for a notch used for notch toughness tests. (e) Scanning electron micrograph of the tip of a typical precrack used for the cracktoughness tests. 

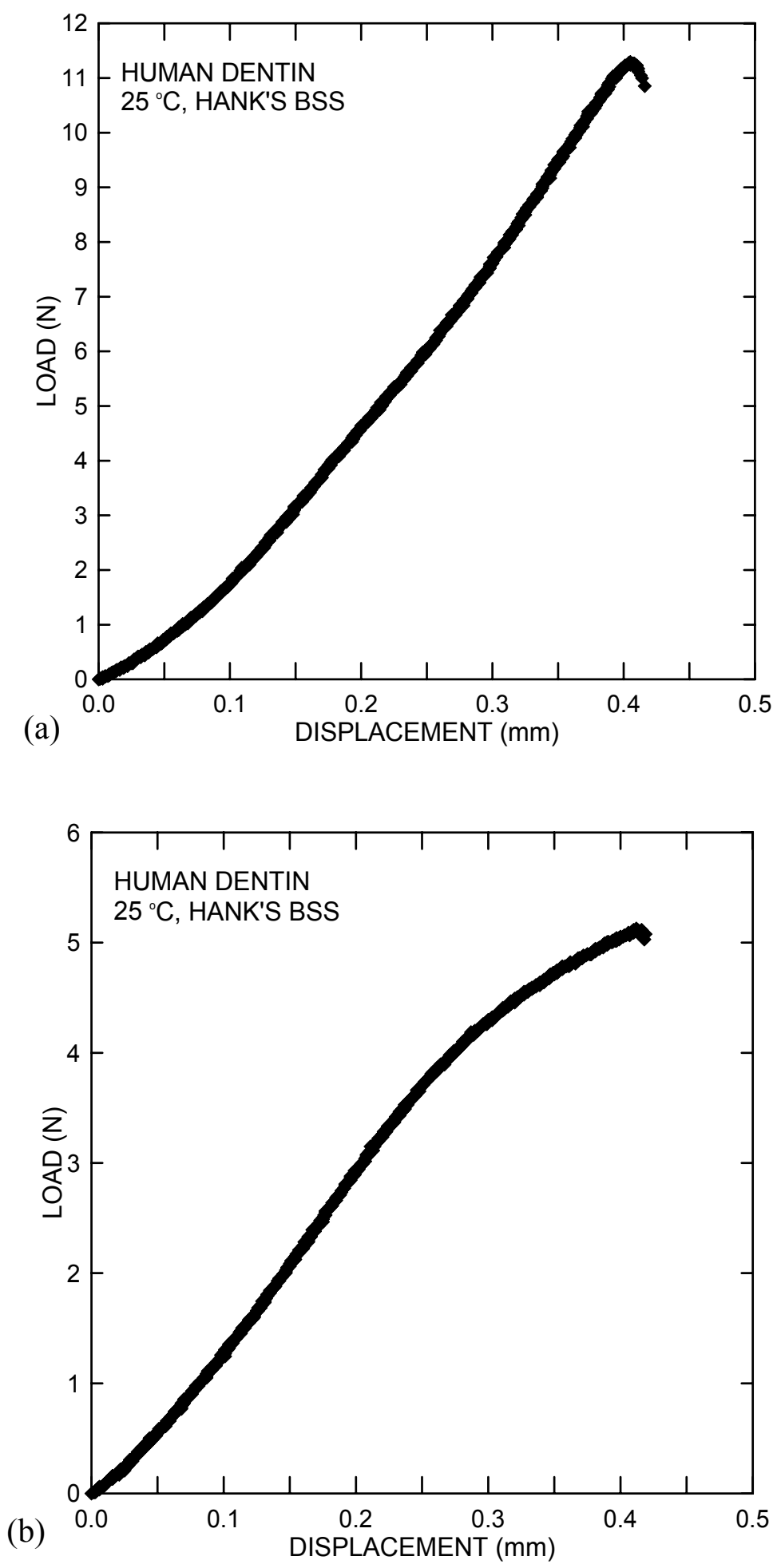

Figure 4 Representative load/displacement curves obtained for the measurement of the fracture toughness ahead of (a) a machined notch and (b) a fatigue precrack. 


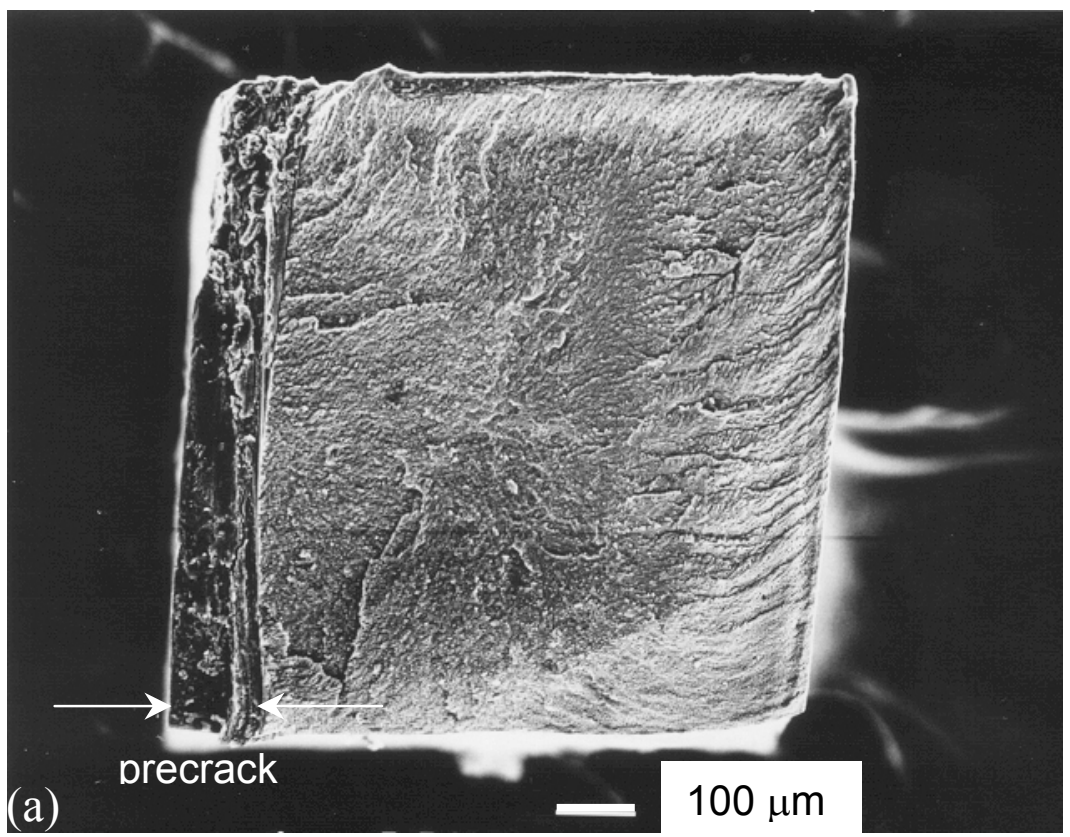

\section{Crack Growth Direction}

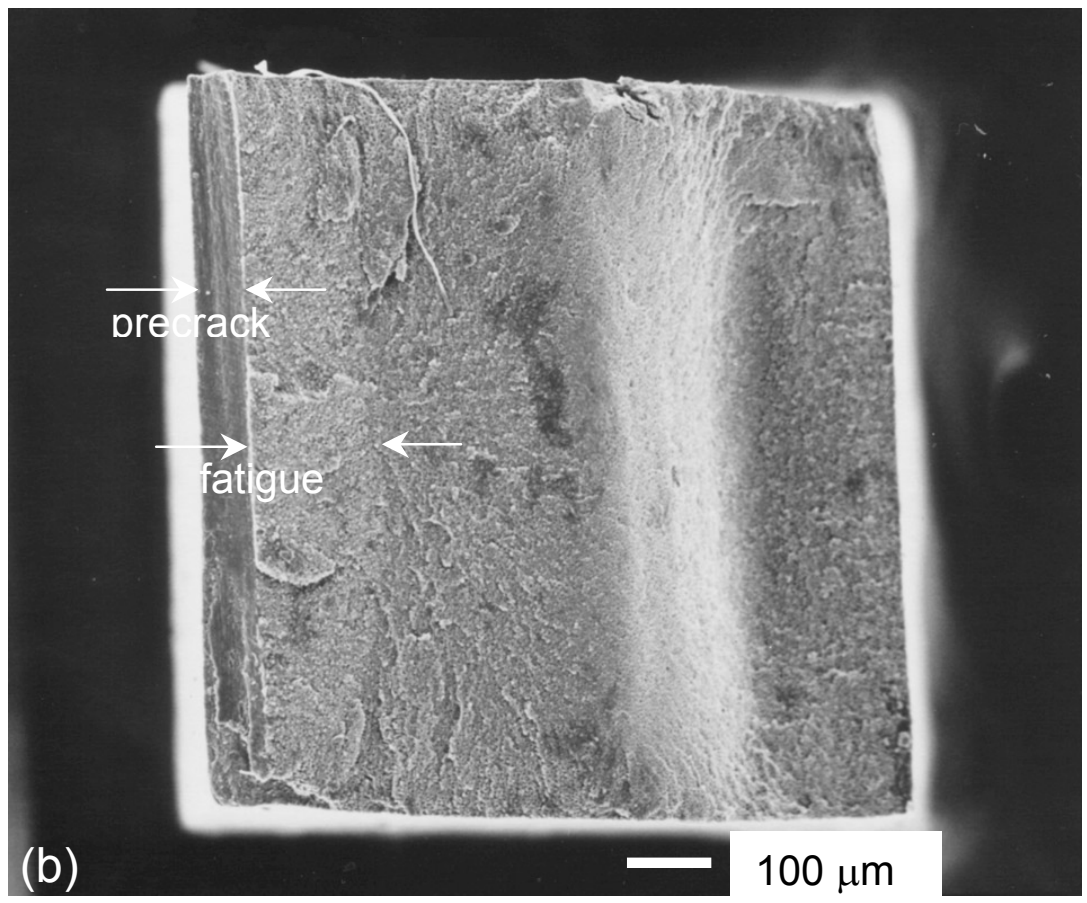

Figure 5 An overview of the fracture surfaces obtained by fracture ahead of (a) a machined notch and (b) a fatigue precrack. The nominal direction of crack growth is also indicated. 


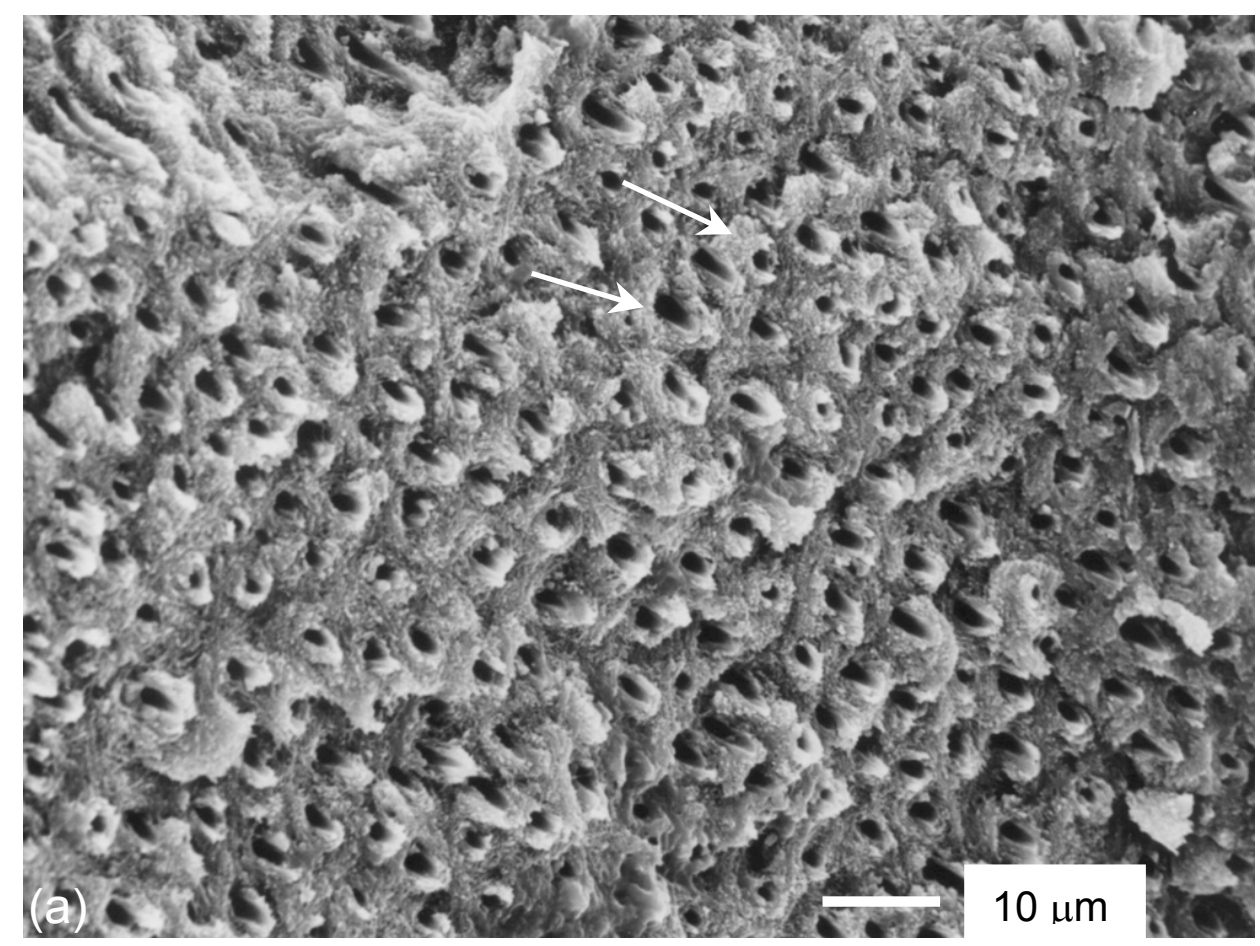

\section{Crack Growth Direction $\longrightarrow$}

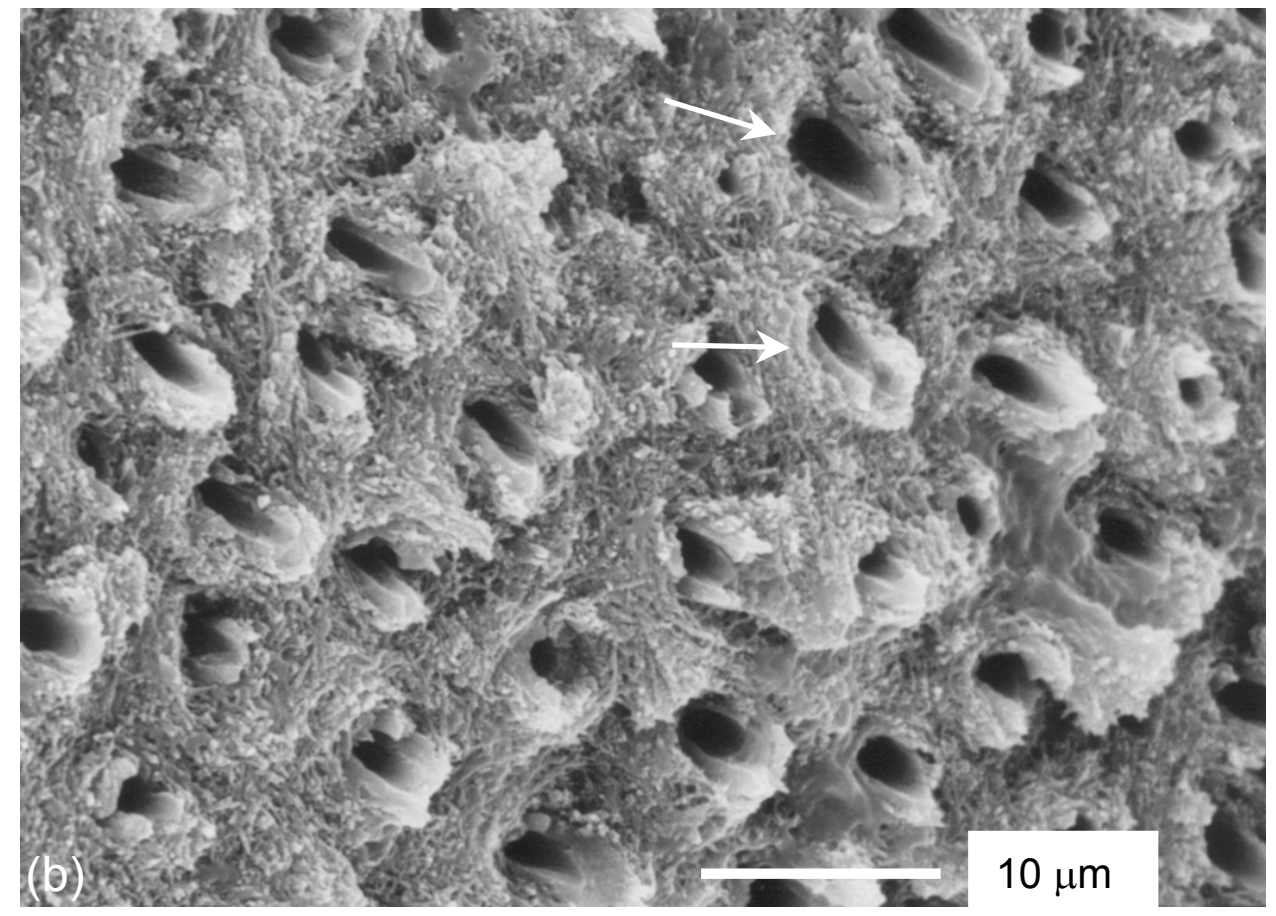

Figure 6 Low- and high-magnification scanning electron micrographs of the cyclic fatigue region of the precrack used for the true $K_{\mathrm{c}}$ determination. There is some evidence of pullout of the peritubular dentin cuffs (indicated by white arrows). The nominal direction of crack growth is also indicated. 


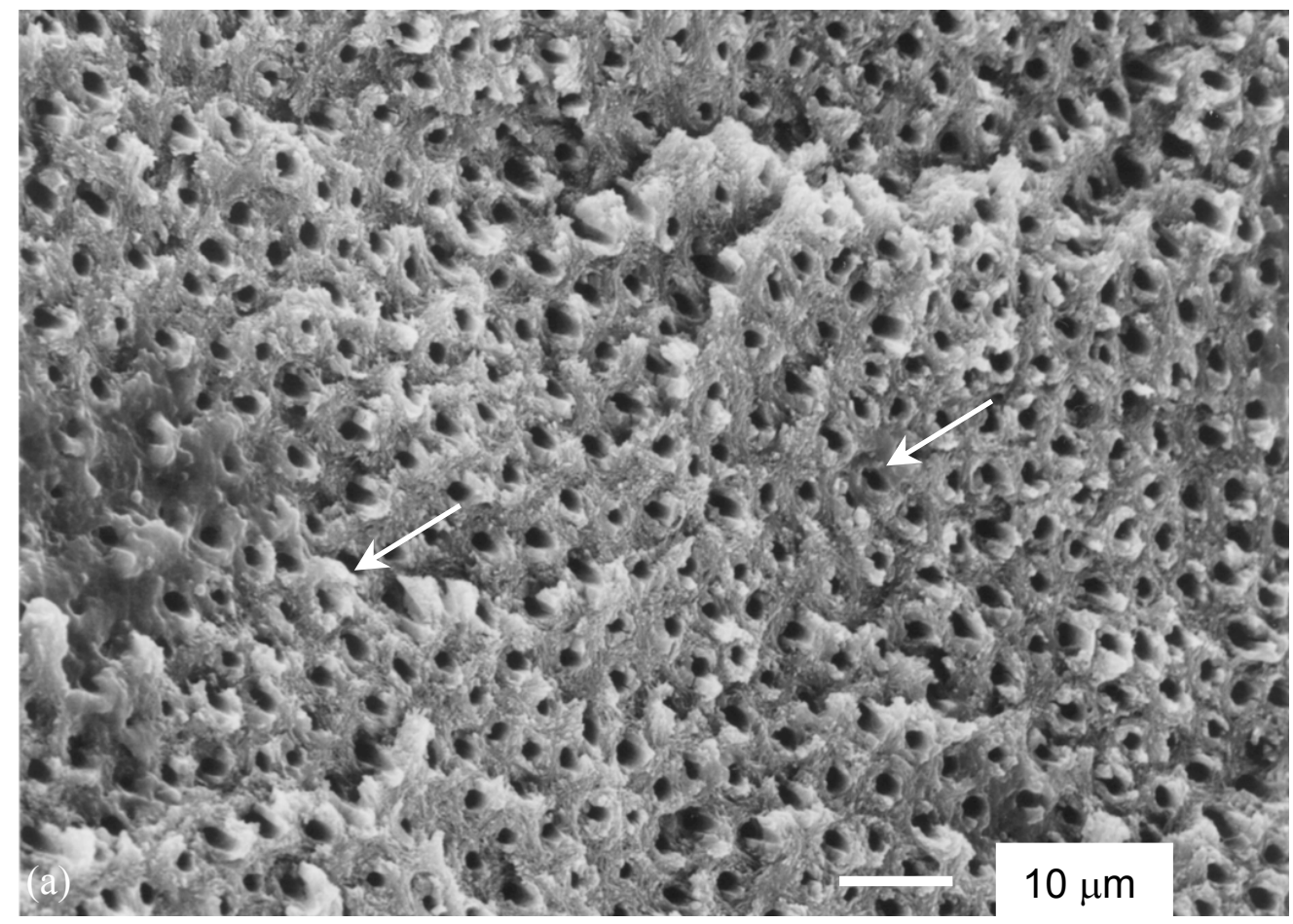

\section{Crack Growth Direction}

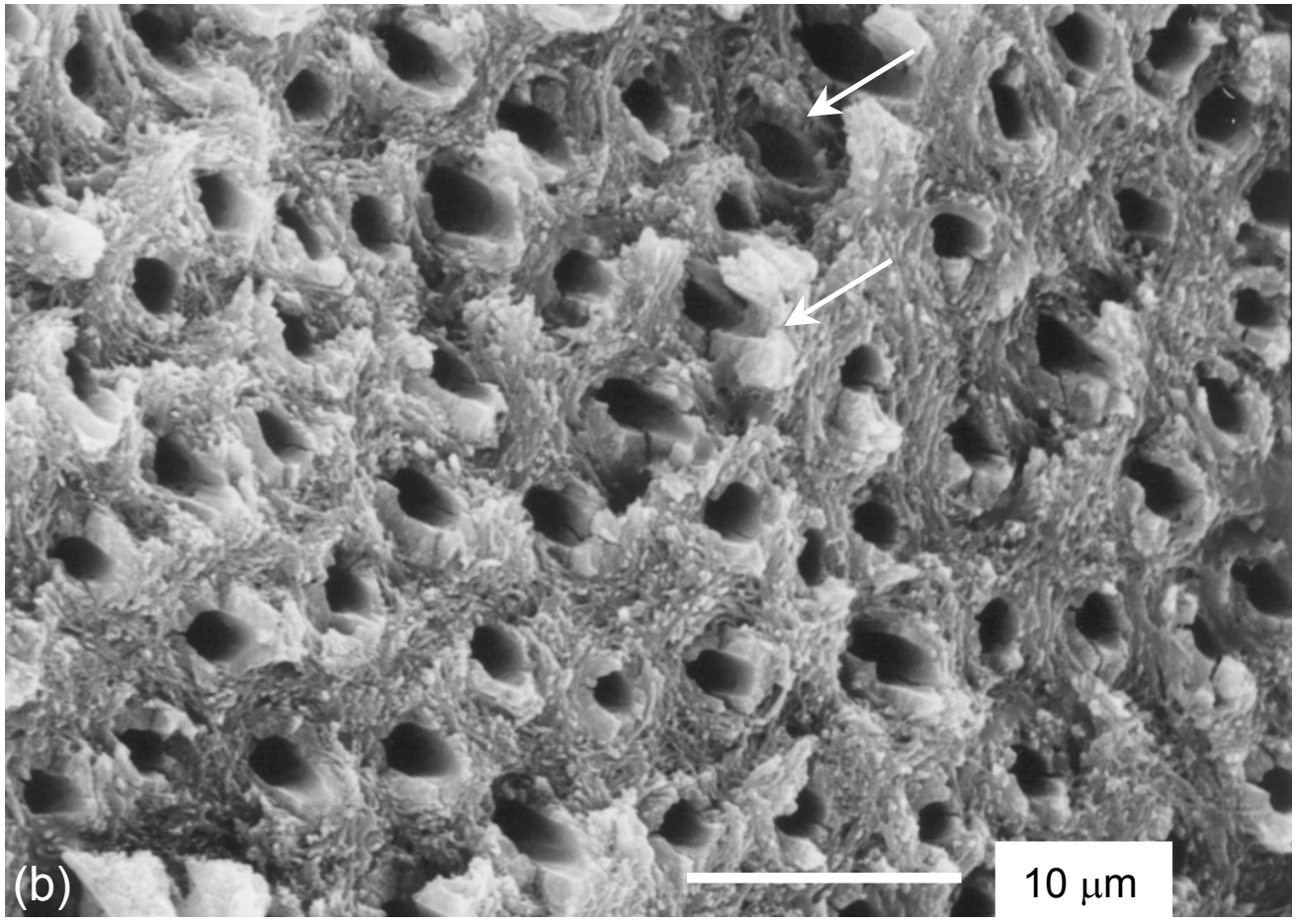

Figure 7 Low- and high-magnification scanning electron micrographs of the overload (fast) fracture region of a specimen used for true $K_{\mathrm{c}}$ determination. It is evident that although this fracture surface is slightly more "rough" at a macroscopic size-scale, it is essentially identical to that obtained by cyclic fatigue at microscopic size-scales. There is again some evidence of pullout of the peritubular dentin cuffs (indicated by white arrows). The nominal direction of crack growth is also indicated. 


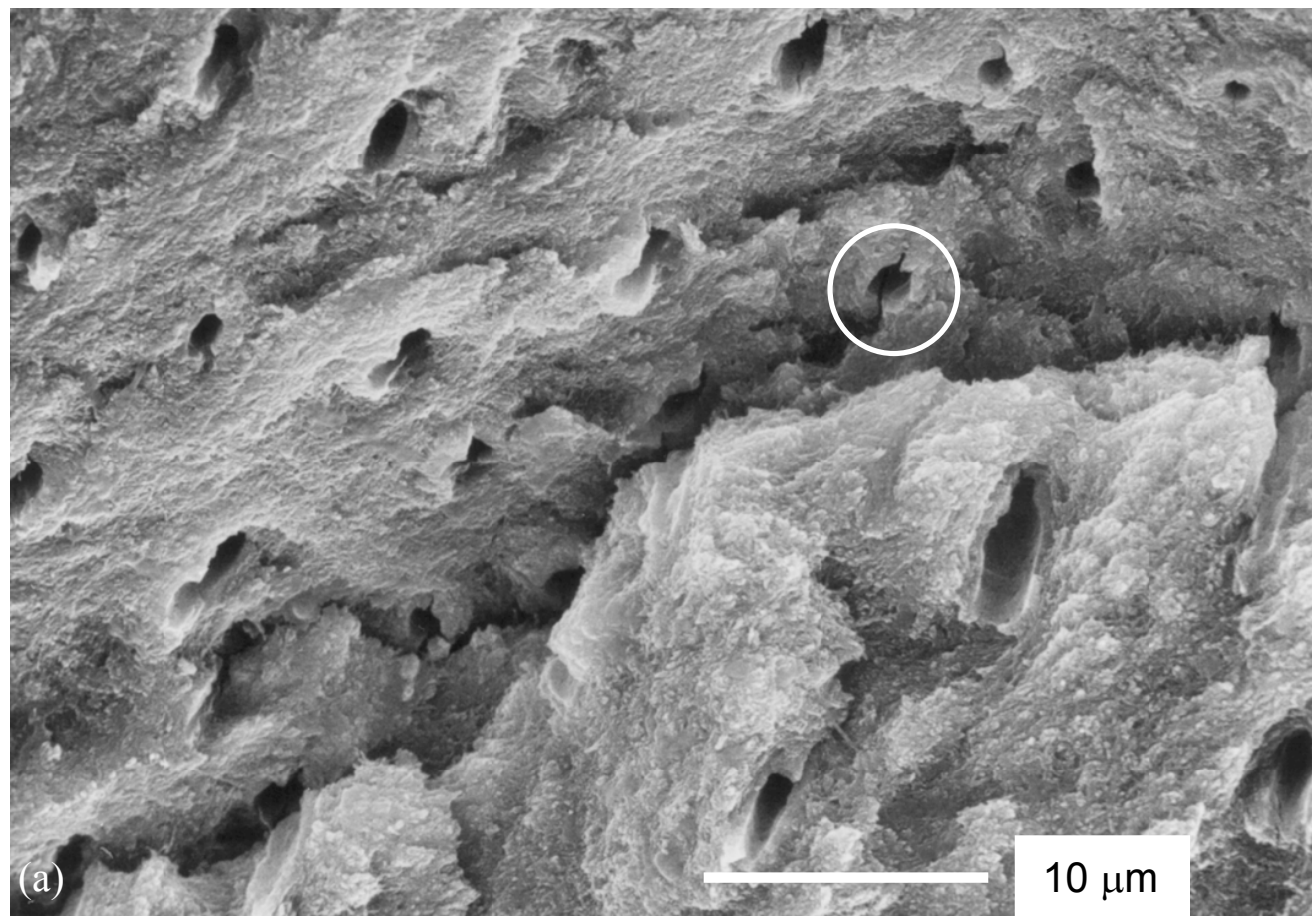

\section{Crack Growth Direction}

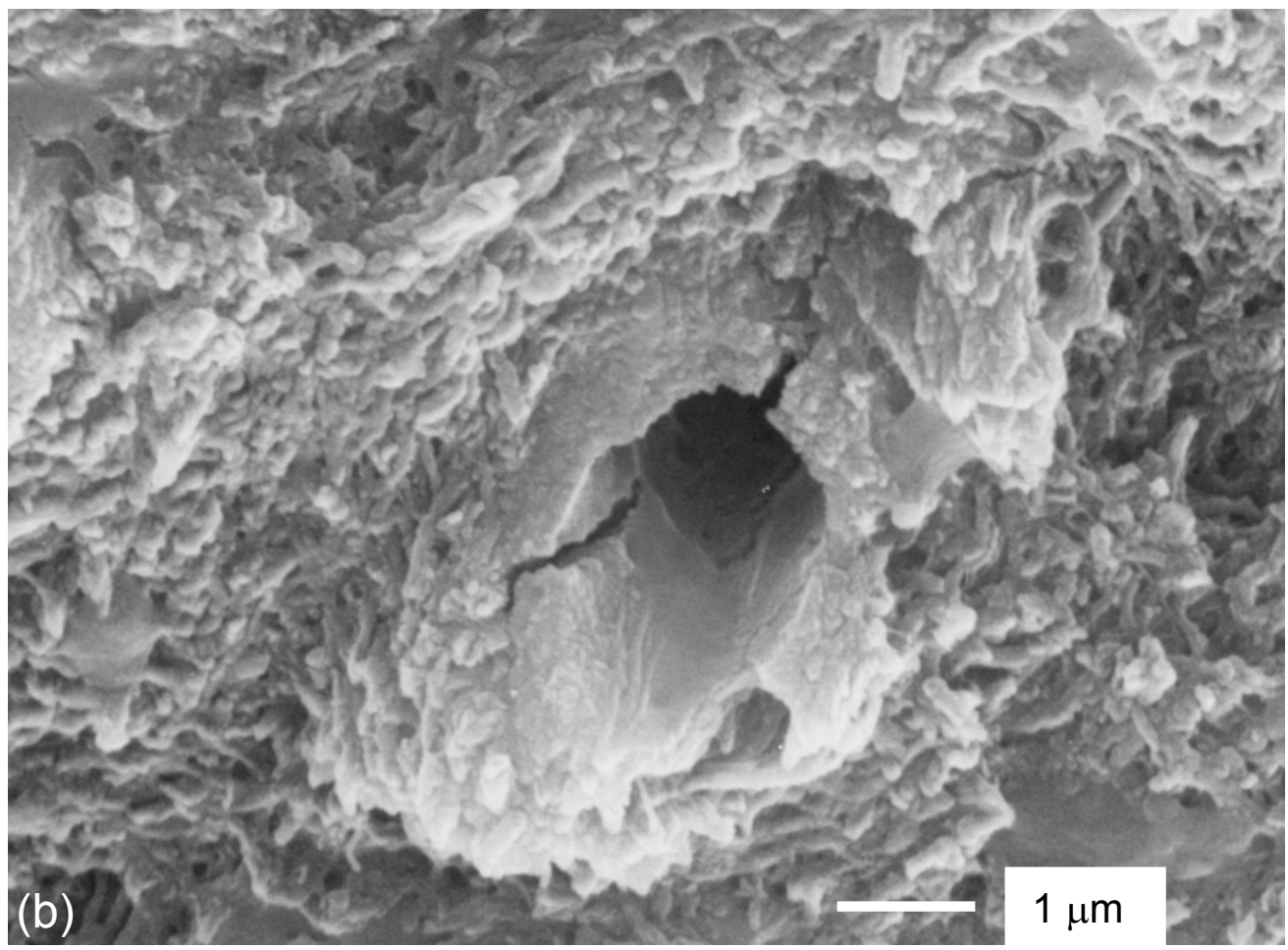

Figure 8 (a) A typical micrograph of the overload fracture region is shown, along with (b) a magnified image of the indicated region. The crack formation in the peritubular dentin is apparent. The nominal direction of crack growth is also indicated. 


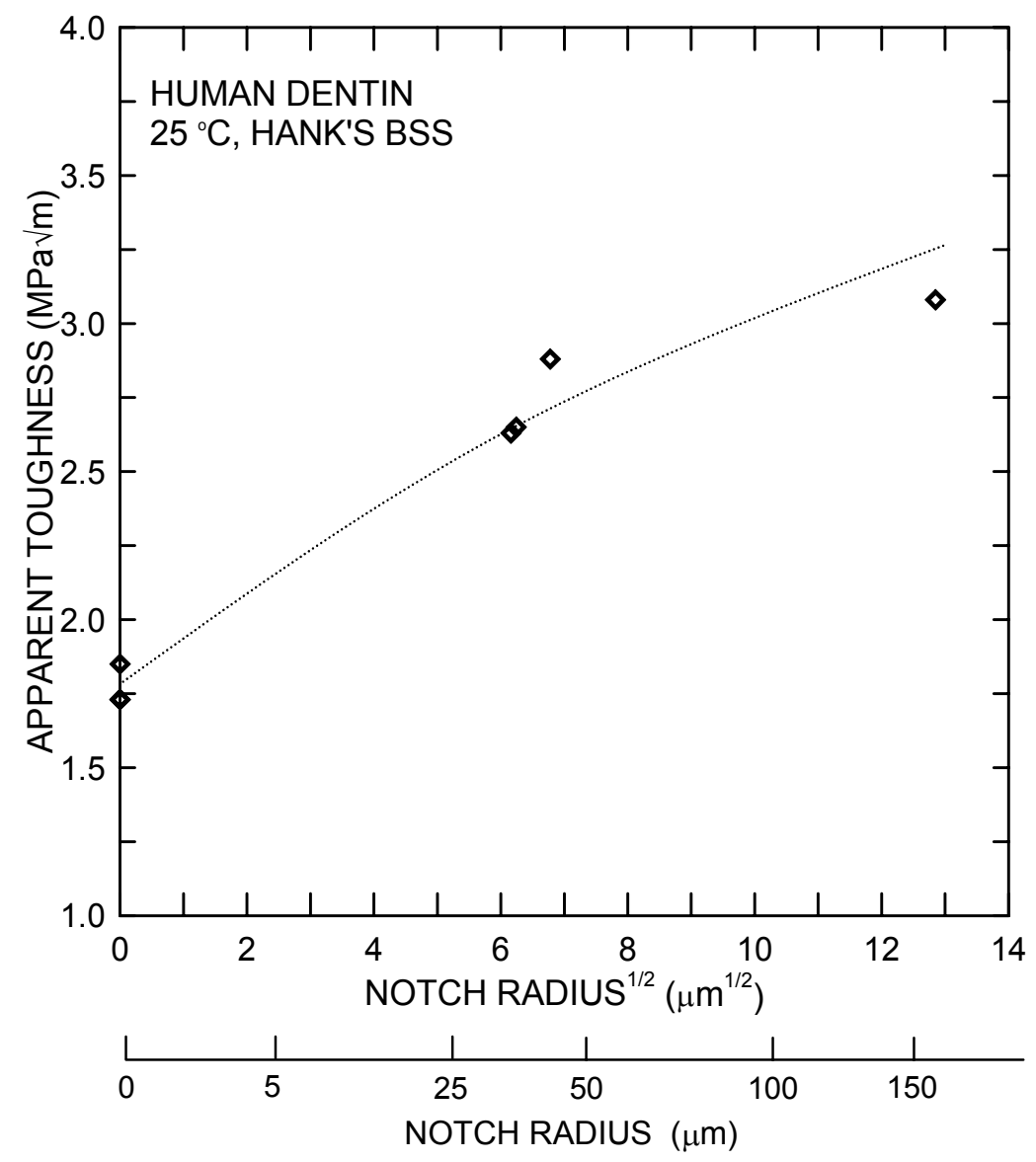

Figure 9 The apparent fracture toughness values for dentin are plotted as a function of the square root of the notch root radius. The corresponding notch radii are also shown. Results are shown for the present investigation along with the single data point of el Mowafy et al. [6] for comparison. 